\title{
BMJ Open Injuries caused by pets in Asian urban households: a cross-sectional telephone
} survey

\author{
Emily Y Y Chan, ${ }^{1}$ Yang Gao, ${ }^{2 \#}$ Liping Li ${ }^{3}$ Po Yi Lee ${ }^{1}$
}

To cite: Chan EYY, Gao Y, Li L, et al. Injuries caused by pets in Asian urban households: a cross-sectional telephone survey. BMJ Open 2017;7:e012813.

doi:10.1136/bmjopen-2016012813

- Prepublication history for this paper is available online. To view these files please visit the journal online (http://dx.doi.org/10.1136/ bmjopen-2016-012813).

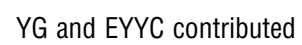
equally.

Received 30 May 2016 Revised 2 November 2016 Accepted 10 November 2016

CrossMark

For numbered affiliations see end of article.

Correspondence to Professor Emily YY Chan; emily.chan@cuhk.edu.hk

\section{ABSTRACT}

Objectives: Little is known about pet-related injuries in Asian populations. This study primarily aimed to investigate the incidence rate of pet-related household injuries in Hong Kong, an urban Chinese setting.

Setting: Cantonese-speaking non-institutionalised population of all ages in Hong Kong accessible by telephone land-line.

Participants: A total of 43542 telephone numbers were dialled and 6570 residents successfully completed the interviews.

Primary and secondary outcome measures: Data of pet-related household injuries in the previous 12 months, pet ownership and socio-demographic characteristics were collected with a questionnaire. Direct standardisation of the incidence rates of petrelated household injuries by gender and age to the 2009 Hong Kong Population Census was estimated. Univariate and multivariate analyses were performed to estimate risks of socio-demographic factors and pet ownership for the injury.

Results: A total of 84 participants experienced petrelated household injuries in the past 12 months, with an overall person-based incidence rate of $1.28 \%$. The majority of the victims were injured once $(69.6 \%)$. Cats $(51.6 \%)$ were the most common pets involved. Pet owners were at an extremely higher risk after controlling for other factors (adjusted OR: 52.0, 95\% $\mathrm{Cl} 22.1$ to 98.7). Females, the unmarried, those with higher monthly household income and those living in lower-density housing were more likely to be injured by pets.

Conclusions: We project a pet-related household injury incidence rate of $1.24 \%$ in the general Hong Kong population, with 86334 residents sustaining petrelated injuries every year. Pet ownership puts people at extremely high risk, especially the unmarried. Further studies should focus on educating pet owners to reduce pet-related injuries in urban Greater China.

\section{BACKGROUND}

Human-animal contact is a daily occurrence for most pet owners globally. In urban settings, dogs and cats are the most commonly involved animals. ${ }^{1-4}$ Urban pet ownership is a rising global trend along with economic

\section{Strengths and limitations of this study}

- This study may be the first of its kind focusing on pet-related injuries in Asian urban households.

- Though pet-related household injury incidence rate was as low as $1.24 \%$, the large sample size $(n=6570)$ supported reliable results.

- The cross-sectional design cannot draw a conclusion on any cause-effect relationship.

- The self-reported pet-related injuries may be subject to potential recall bias.

- Limited collection about the details of pet ownership in this study is constrained to develop effective protection measures.

development. China follows this urban trend for dog and cat ownership, and has the third largest dog population and the sixth largest cat population in the world. ${ }^{5}{ }^{6}$ The latest available data have shown that China's pet population has grown by $20 \%$ in 5 years from 1999 to 2004 , largely attributable to the rapid increase in urban areas. ${ }^{6}$ Given its rapid economic development in the past decades, especially the increased size of the population that has more disposable income resulting in affordable pet ownership, petrelated injuries would be expected to increase along with the rising pet ownership rate in urban China.

In the urban settings of high income countries, although victims with moderate to severe pet-related injuries may seek medical attention either in an emergency department or in a physician's office, most minor injuries go unreported, with victims administering first aid by themselves and then often do not seek or require medical attention. ${ }^{3} 7$ In Western high-income communities, young children aged 5-9 years bear most reported pet-related injuries, and dogs are the most commonly involved animals. ${ }^{1-3} 89$ Possession of a pet is found to be associated with a higher risk for animal bites. Adults with two or more dogs in the household were five 
times more likely to be bitten than those living without dogs at home. ${ }^{4}$ In addition, pets are also associated with non-fatal fall-related injuries. An estimated average of 86629 fall injuries each year were associated with cats and dogs, for an average annual injury rate of 29.7 per 100000 population in the USA. ${ }^{4}$ Although there are various case reports and clinic-setting based studies, no studies of pet-related injuries have been conducted among the general population in Asia. There is a knowledge gap in the epidemic of pet-related injuries in this population. Without the knowledge, it is difficult to develop effective preventive strategies.

Hong Kong, located in South China, is a typical welldeveloped urban setting in Asia. Its social and economic developments as well as people's lifestyle have been referred or even copied by many other Asian cities. The pet ownership in Hong Kong is about 20\%, relatively lower than in the Western developed countries (eg, $34.6 \%$ in Australia and $36.5 \%$ in the USA), mainly due to the limited living space and harried lifestyle in Hong Kong. ${ }^{7}$ The knowledge of pet-related injuries in Hong Kong is scarce. A 2008 survey projected that annually 5400 animal bite-related injuries, which were serious enough to limit the normal activities of a person, occurred in the entire Hong Kong population. ${ }^{10}$ That study did not differentiate pets and non-pet animals. In addition, no further information such as incidence rate, distribution in the population and risk factors was reported. This study primarily aimed to investigate the incidence rate of non-fatal pet-related household injuries in Hong Kong. In addition, we also examined the associations of the socio-demographic characteristics and pet ownership with the injury. Results of the study provided better understanding about pet-related injuries in urban Asia, which can be used to develop effective strategies to reduce pet-related injuries in Asian population.

\section{METHODS}

Participants

A cross-sectional, population-based telephone survey was conducted during April to June, 2009. The target population was the Cantonese-speaking non-institutionalised population of all ages in Hong Kong. The Hong Kong population in 2009 was 6.97 million, of which about 95.8\% were Cantonese speakers or able to use Cantonese. ${ }^{11}$ Over $95 \%$ of the households in Hong Kong had a land-line telephone. ${ }^{12}{ }^{13}$ Telephone numbers were randomly selected from current telephone directories. Telephone calls were made during weekday evenings (6:30 pm to 10:00 pm, Monday to Friday) and during daytime on the weekends (Saturday and Sunday) in order to avoid an over-representation of people not working. An eligible member (defined as a Chinese-speaking Hong Kong resident without hearing impairment) was selected from each of the contacted households. If more than one member was eligible in the same household, the one whose birthday closest to the survey date was invited to participate into the study. If the selected member was under 16 years old, the adult member who knew the selected person most was invited to respond to the telephone interview. At least five calls were dialled at different time slots before we considered the number invalid and gave up. All telephone interviews were conducted by trained investigators. Verbal consent was obtained from the adult participants and parental verbal consent was sought for those aged under 18.

\section{Sample size estimation}

The telephone survey had a focus on all types of injuries occurring in household settings. Thus, the sample size was estimated based on the incidence rate of all nonfatal unintentional household injuries. Our pilot study, conducted in May-June 2007 among 1001 participants, indicated an incidence rate of all household injuries of $25 \%$. After calculation, a sample size of 6500 yielded a $95 \%$ CI with a precision of $1.0 \%$ for an estimated rate of $25 \%(\beta=0.80$ and $\alpha=0.05)$.

\section{Data collection and measures}

A modified Chinese-language questionnaire based on the WHO's Guidelines for Conducting Community Surveys on Injuries and Violence was used. ${ }^{14}$ The questionnaire has been proved to be reliable and valid in our previous studies. ${ }^{12}$ All participants were asked about the following items.

Pet-related household injury: it was defined as unintentional, non-fatal physical damage to the human body caused by pets (eg, pet bites, pet scratches, falls caused by pets, etc), which took place in a household environment, including in the common areas of their residence such as clubhouses, common entry ways, car parks, stairwells or inside an elevator. A pet in this study was defined as any domesticated or tamed animal that is kept as a companion and cared for affectionately, including cats, dogs, rabbits, birds, guinea pigs, hamsters and so forth. Types and frequencies of this type of injury in the previous 12 months were asked. For those who indicated a pet-related injury as the most recent injury, the following information was further collected from them: day and place of that injury, body part(s) injured, human-pet interaction before the injury, ownership of the pet involved (pet ownership was defined as the pet owned by the family of the injured person), vaccination of that pet (eg, rabies vaccination, vaccination against distemper, parvovirus, hepatitis, leptospirosis and kennel cough for dogs and vaccination against feline enteritis for cats), whether attacked by the same pet before, treatment of that injury, absence from work or school caused by the injury and recovery time of the injury.

Socio-demographic and other factors: gender, age, marital status, education attainment, occupation and employment status, monthly household income, family size, type and size of the living area (square feet, $\mathrm{ft}^{2}$ ), living 
density $\left(\mathrm{ft}^{2} /\right.$ person) and time spent at home (hours/ day) were collected from the participants.

\section{Statistical analysis}

Data were analysed with the IBM SPSS Statistics (V.20). Overall, gender-specific and age-specific incidence rates of pet-related injuries in the previous 12 months were calculated. Direct standardisation of the incidence rate by gender and age was used to project the incidence of pet-related injuries in the entire Hong Kong population, indicated by the number of people injured and the overall incidence rate. ${ }^{16} \chi^{2}$ test was performed to analyse between-group differences in pet-related injuries. Univariate and multivariate logistic regression were fitted to estimate the risks of the socio-demographics and other confounding factors for the injury before and after adjustment for each other. In the univariate analyses, Bonferroni correction was applied to counteract the problem of multiple comparisons. Significance levels of $\alpha=0.0125(0.05 / 4)$ and $\alpha=0.00417(0.05 / 12)$ were therefore adopted respectively in comparisons between the study participants and the Hong Kong population (2009) and those between injured and non-injured participants. In the multivariate analyses, a hierarchical approach was adopted, with first regressing the sociodemographic factors (Model 1), and then entering pet ownership (Model 2). All socio-demographic variables in Model 1 were forwardly selected (Wald method) using $\mathrm{p}<0.10$ as the entry and removal criteria. OR and $95 \%$ CI were then derived.

\section{RESULTS}

A total of 43542 telephone numbers were dialled, in which 12479 were successfully reached and 10380 were with people eligible for the study (figure 1). Among the eligible people, $6723(64.8 \%)$ agreed to participate into the study and were interviewed and $6570(63.3 \%)$ successfully completed the interviews and with their data analysed. It was found a minor but significant difference (using $\alpha=0.0125$ ) in age distribution between the study participants and the general Hong Kong population, with our participants having slightly more children and young adults (table 1). In addition, our study had significantly more participants with higher education levels and doing a white-collar job, compared with the general population.

The overall person-based incidence rate of pet-related household injuries was $1.28 \% \quad(n=84)$. Seventy-nine injured participants reported the injury frequency in the past 12 months, including $69.6 \%(\mathrm{n}=55)$ experienced such injuries once, $17.7 \% \quad(n=14)$ did twice or three times and $12.7 \% \quad(n=10)$ did four times or more. The remaining five injured persons were unable to remember the number of injuries. Only one injury was caused by a related fall. The direct age/gender standardisation of rates estimated that annually 86334 Hong Kong residents experienced pet-related household injuries, with an overall incidence rate of $1.24 \%$.

There were significant differences in the distribution of age, marital status, size of living area and pet ownership according to the significance level of 0.00417 (table 2). Of the injured participants, 64 (76.2\%)

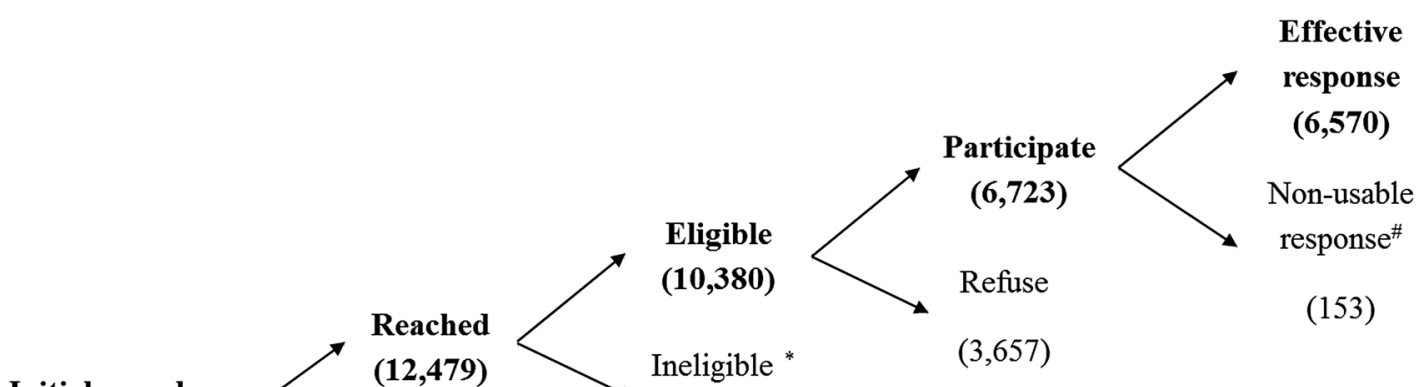

Initial sample selected

$(43,542)$

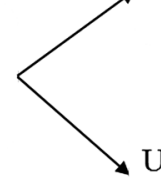

$(12,479)$

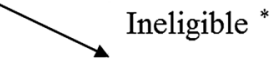

$(2,099)$

Unreachable $(31,063)$

$(8,303$ with invalid telephone number +

22,760 unreachable after five attempts)

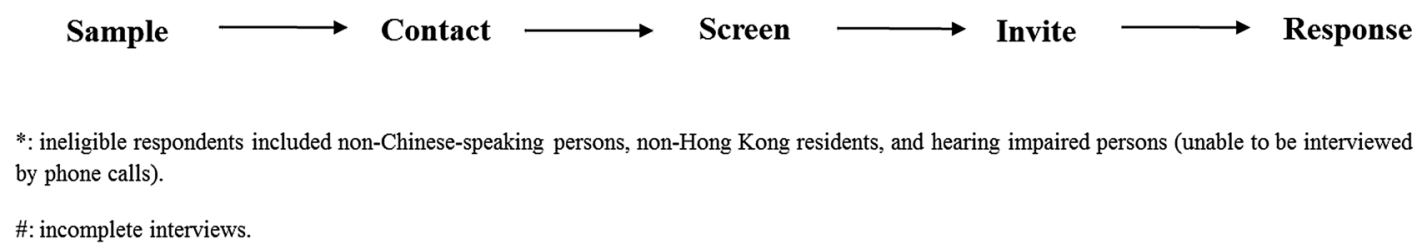

Figure 1 Recruitment process of study participants. 
Table 1 Comparisons of major socio-demographic characteristics between the study participants and the Hong Kong population 2009

\begin{tabular}{|c|c|c|c|c|c|}
\hline \multirow[b]{2}{*}{ Gender $(\mathrm{N}=6561)$} & \multicolumn{2}{|c|}{$\begin{array}{l}\text { Study } \\
\text { participants } \\
\text { n \% }\end{array}$} & \multicolumn{2}{|c|}{$\begin{array}{l}\text { Hong Kong } \\
\text { population } \\
(2009) \dagger \\
n \%\end{array}$} & \multirow{2}{*}{$\frac{\text { p Value of } \chi^{2} \text { test }}{0.042}$} \\
\hline & & & & & \\
\hline Male & 3173 & 48.4 & 3284800 & 47.7 & \\
\hline Female & 3388 & 51.6 & 3688000 & 52.3 & \\
\hline Age (years, $\mathrm{N}=6503$ ) & & & & & $<0.001$ \\
\hline $0-14$ & 887 & $13.6^{*}$ & 863800 & $12.4^{\star}$ & \\
\hline $15-24$ & 906 & $13.9^{*}$ & 885400 & $12.7^{\star}$ & \\
\hline $25-44$ & 2070 & $31.8^{*}$ & 223690 & $32.1^{*}$ & \\
\hline $45-64$ & 1837 & $28.2^{*}$ & 2088100 & $29.9^{*}$ & \\
\hline$\geq 65$ & 803 & $12.3^{*}$ & 898600 & $12.9^{\star}$ & \\
\hline Education in population aged 15 or above $(\mathrm{N}=5559)$ & & & & & $<0.001$ \\
\hline Primary or below & 932 & $16.8^{*}$ & 1589800 & $22.8^{*}$ & \\
\hline Secondary & 2.994 & $53.9^{\star}$ & 3611900 & $51.8^{*}$ & \\
\hline Postsecondary $\ddagger$ & 1633 & $29.4^{*}$ & 1771100 & $25.4^{*}$ & \\
\hline Occupation in working population $(\mathrm{N}=2873)$ & & & & & $<0.001$ \\
\hline White-collar job§ & 2376 & $82.7^{*}$ & 2351200 & $67.7^{\star}$ & \\
\hline Blue-collar jobף & 462 & $16.1^{*}$ & 1111500 & $32.0^{\star}$ & \\
\hline Others & 35 & $1.2^{*}$ & 5000 & $0.1^{*}$ & \\
\hline
\end{tabular}

*Significant difference reached in the $\chi^{2}$ test by using the actual number of population. Bonferroni correction was applied to correct multiple testing. A significance level of $a=0.0125(0.05 / 4)$ was therefore adopted.

†Data sources: Hong Kong annual digest of statistics 2012 edition.

†Postsecondary education included non-degree and degree courses.

$\S$ White-collar job: including manager and administrators, professionals, associate professionals, clerical support workers and service and sales workers.

I|Blue-collar job: including craft and related workers, plant and machine operators, elementary occupations and skilled agricultural and fishery workers.

reported a pet-related injury as the most recent injury. No significant difference in the distribution of any factor was found between the two groups (those who were injured by a pet and those who reported a petrelated injury as the most recent injury). Table 3 provides the results of the pet-related injuries among those reporting a pet-related injury as their most recent injury. Hands $(79.7 \%)$ were the most common body part injured. Cats $(51.6 \%)$ and dogs $(42.2 \%)$ were the most common pets involved. The majority of the involved pets belonged to the victims $(92.2 \%)$ and had ever received vaccinations beforehand $(70.3 \%)$. The majority of the injured participants $(62.5 \%)$ dealt with the injury by themselves. Only one case sought medical care at a Chinese medicine clinic, with a total expenditure of HK $\$ 330$ (around US\$42.5) for two visits, consisting of HK $\$ 310$ (around US $\$ 40.0$ ) for the medical cost and HK\$20 (around US\$2.5) for the transport cost.

Table 4 presents incidence rates and risk estimates of socio-demographic factors and pet ownership for the injury. In the univariate analyses, young adults (1524 years old, with age $\geq 45$ as reference), the unmarried, those with the highest monthly household income $(\geq$ HK $\$ 30000)$, those living in the biggest house $\left(>700 \mathrm{ft}^{2}\right)$ and pet owners were significantly more likely to be injured (using $\alpha=0.00417$ ), while retired participants were significantly less likely to experience pet-related injury (with those in a white-collar job as reference, $\alpha=0.00417$ ). In the multivariate Model 1 , where the selected socio-demographic factors were controlled for each other, females, the unmarried, those with higher monthly household income and those with lower density residences were significantly at higher risks for the injury ( $\alpha=0.05$ for all multivariate analyses). In addition, increasing risks of monthly household income and living density were observed for pet-related injury. After controlling for pet ownership (Model 2), only the elevated risks of unmarried participants and the highest monthly household income $(\geq \mathrm{HK} \$ 30000)$ remain significant (adjusted OR=1.80, 95\% CI 1.04 to 3.10, $\mathrm{p}=0.035$ and adjusted $\mathrm{OR}=7.60,95 \%$ CI 1.01 to 57.1 , $\mathrm{p}=0.049$ respectively). In addition, pet owners were at extremely higher risk for the injury (adjusted $\mathrm{OR}=52.0$, 95\% CI 22.1 to $122.4, \mathrm{p}<0.001$ ).

Considering that it is a strong factor, we further performed univariate and multivariate logistic regression after stratification by pet ownership. Among non-pet owners, no socio-demographic characteristic was significantly related to pet-related injuries in $\chi^{2}$ and multivariate analyses. Among pet owners, univariate logistic regression revealed that age group, marital status and living density were significantly related to pet-related injuries, while only marital status remains significance in the multivariate model, with unmarried participants 
Table 2 Characteristics of the participants by pet-related injury in the past year

\begin{tabular}{|c|c|c|c|c|c|c|}
\hline & $\begin{array}{l}\text { No pe } \\
\text { injury } \\
\text { ( } N=64 \\
n \%\end{array}$ & & $\begin{array}{l}\text { Pet } \\
\text { inju } \\
\text { ( } \mathrm{N}= \\
\text { n \% }\end{array}$ & & $\begin{array}{l}\text { Pet } \\
\text { inj } \\
\text { late } \\
\text { ( } N= \\
\mathrm{n}=\end{array}$ & \\
\hline Gender & & & & & & \\
\hline Male & 3140 & 48.5 & 33 & 39.3 & 29 & 45.3 \\
\hline Female & 3337 & 51.5 & 51 & 60.7 & 35 & 54.7 \\
\hline Age (years) & & & & & & \\
\hline $0-4$ & 198 & $3.1^{*}$ & 4 & $4.9^{*}$ & 1 & 1.6 \\
\hline $5-14$ & 676 & $10.5^{*}$ & 9 & $11.0^{*}$ & 6 & 9.4 \\
\hline $15-24$ & 884 & $13.8^{*}$ & 22 & $26.8^{*}$ & 17 & 26.6 \\
\hline $25-44$ & 2042 & $31.8^{*}$ & 28 & $34.1^{*}$ & 26 & 40.6 \\
\hline$\geq 45$ & 2621 & $40.8^{*}$ & 19 & $23.2^{*}$ & 14 & 21.9 \\
\hline $45-64$ & 1818 & $28.3^{*}$ & 19 & $23.2^{*}$ & 14 & 21.9 \\
\hline$\geq 65$ & 803 & $12.5^{\star}$ & 0 & $0.0^{*}$ & 0 & 0.0 \\
\hline Marital status & & & & & & \\
\hline Married/cohabiting & 3489 & $54.3^{*}$ & 30 & $36.6^{*}$ & 22 & 34.9 \\
\hline Unmarried (single/divorced/widowed) & 2936 & $45.7^{*}$ & 52 & $63.4^{*}$ & 41 & 65.1 \\
\hline Education & & & & & & \\
\hline Primary or below & 1447 & 23.0 & 9 & 11.0 & 6 & 9.5 \\
\hline Secondary & 3206 & 51.0 & 46 & 56.1 & 31 & 49.2 \\
\hline Postsecondary† & 1628 & 25.9 & 27 & 32.9 & 26 & 41.3 \\
\hline Occupational status & & & & & & \\
\hline White-collar job $\ddagger$ & 2370 & 37.2 & 41 & 49.4 & 34 & 54.0 \\
\hline Blue-collar job§ & 469 & 7.4 & 2 & 2.4 & 1 & 1.6 \\
\hline Housewives & 846 & 13.3 & 8 & 9.6 & 5 & 7.9 \\
\hline Retired & 921 & 14.5 & 3 & 3.6 & 3 & 4.8 \\
\hline Students & 1444 & 22.7 & 25 & 30.1 & 17 & 27.0 \\
\hline Others & 315 & 4.9 & 4 & 4.8 & 3 & 4.8 \\
\hline Monthly household income (HK\$ף) & & & & & & \\
\hline$<10000$ & 942 & 18.6 & 3 & 4.5 & 4 & 7.7 \\
\hline $10000-19999$ & 1422 & 28.0 & 19 & 28.4 & 16 & 30.8 \\
\hline $20000-29999$ & 1035 & 20.4 & 12 & 17.9 & 4 & 7.7 \\
\hline$\geq 30000$ & 1677 & 33.0 & 33 & 49.3 & 28 & 53.8 \\
\hline Family size (persons) & & & & & & \\
\hline $2-4$ & 4732 & 73.7 & 62 & 75.6 & 48 & 75.0 \\
\hline$\geq 5$ & 1325 & 20.6 & 17 & 20.7 & 13 & 20.3 \\
\hline Living along (1 person) & 364 & 5.7 & 3 & 3.7 & 3 & 4.7 \\
\hline Type of housing & & & & & & \\
\hline Public housing & 1826 & 28.3 & 16 & 19.0 & 11 & 17.2 \\
\hline Subsidised housing & 993 & 15.4 & 12 & 14.3 & 9 & 14.1 \\
\hline Private housing & 3555 & 55.1 & 54 & 64.3 & 42 & 65.6 \\
\hline Others & 77 & 1.2 & 2 & 2.4 & 2 & 3.1 \\
\hline Size of living area $\left(\mathrm{ft}^{2} \S\right)$ & & & & & & \\
\hline$\leq 400$ & 1645 & $27.7^{*}$ & 13 & $18.3^{*}$ & 11 & 20.0 \\
\hline $401-600$ & 1932 & $32.5^{*}$ & 14 & $19.7^{*}$ & 15 & 27.3 \\
\hline $601-700$ & 901 & $15.2^{*}$ & 16 & $22.5^{*}$ & 9 & 16.4 \\
\hline$>700$ & 1463 & $24.6^{*}$ & 28 & $39.4^{*}$ & 20 & 36.4 \\
\hline Living density ( $\mathrm{ft}^{2} /$ person§) & & & & & & \\
\hline$<120$ & 1511 & 25.5 & 9 & 12.9 & 9 & 16.4 \\
\hline $120-159$ & 1288 & 21.8 & 13 & 18.6 & 11 & 20.0 \\
\hline $160-249$ & 1985 & 33.5 & 29 & 41.4 & 21 & 38.2 \\
\hline$\geq 250$ & 1136 & 19.2 & 19 & 27.1 & 14 & 25.5 \\
\hline Time spent at home (hours/day) & & & & & & \\
\hline$\leq 12$ & 3074 & 47.8 & 40 & 48.2 & 32 & 50.0 \\
\hline $13-18$ & 2629 & 40.8 & 34 & 41.0 & 23 & 35.9 \\
\hline$>18$ & 734 & 11.4 & 9 & 10.8 & 9 & 14.1 \\
\hline
\end{tabular}


Table 2 Continued

\begin{tabular}{|c|c|c|c|c|c|c|}
\hline & $\begin{array}{l}\text { No pe } \\
\text { injury } \\
\text { ( } N=64 \\
n \%\end{array}$ & & $\begin{array}{l}\text { Pet } \\
\text { inju } \\
(\mathrm{N}= \\
\mathrm{n} \%\end{array}$ & & $\begin{array}{l}\text { Pet- } \\
\text { inju } \\
\text { late } \\
(\mathrm{N}= \\
\mathrm{n} \%\end{array}$ & \\
\hline Pet owr & & & & & & \\
\hline No & 5675 & $87.9^{\star}$ & 11 & $13.1^{*}$ & 5 & 7.8 \\
\hline Yes & 780 & $12.1^{*}$ & 73 & $86.9^{*}$ & 59 & 92.2 \\
\hline $\begin{array}{l}{ }^{*} \text { Significe } \\
\text { a=0.004 } \\
\text { †Postse } \\
\text { fWhite-c } \\
\text { workers. } \\
\text { §Blue-cc } \\
\text { workers. } \\
\text { १Annual } \\
\S 1 \mathrm{ft}^{2}=0 .\end{array}$ & $\begin{array}{l}\text { t. Bonfe } \\
\text { t differer } \\
\text { gree co } \\
\text {, profes } \\
\text { nt and n } \\
1=\text { HK\$ }\end{array}$ & $\begin{array}{l}\text { ftion wa } \\
\text { found be } \\
\text { ssociate } \\
\text { perators } \\
\$ 10000\end{array}$ & $\begin{array}{l}\text { O cor } \\
\text {-relat } \\
\text { nals, } \\
\text { ary oc } \\
\text { 0; HK }\end{array}$ & $\begin{array}{l}\text { ole testin } \\
\text { and pet-r } \\
\text { upport } \\
\text { s and sk } \\
=\text { US } \$ 25\end{array}$ & $\begin{array}{l}\text { cance } \\
\text { ry as } \\
\text { dd sen } \\
\text { ultura } \\
000=\end{array}$ & $\begin{array}{l}\text { njury. } \\
\text { sales } \\
\text { ery } \\
0 .\end{array}$ \\
\hline
\end{tabular}

being at higher risk (adjusted OR=2.25, 95\% CI 1.28 to $3.96, \mathrm{p}=0.005)$.

\section{DISCUSSION}

This study found a person-based incidence rate of petrelated household injury of $1.28 \%$ in the previous 12 months among 6570 residents in Hong Kong. Using the direct age/gender standardisation rates, an overall incidence rate of $1.24 \%$ was projected for the entire Hong Kong population, with an estimation of 86334 residents injured by pets annually. In our participants, the majority of the injured participants were bitten by pets once $(69.6 \%)$, with hands as the body part most commonly injured $(79.7 \%)$, and $98.4 \%$ did not seek medical attention. Cats $(51.6 \%)$ were the most common pets causing injury, followed by dogs $(42.2 \%)$. Most of the pets belonged to the injured $(92.2 \%)$. Pet owners were at extremely higher risk for such injuries. In addition, females, the unmarried, those with higher monthly household income and those living in lower density housing were more likely to be injured by pets.

This study may be the first of its kind focusing on petrelated household injuries in the general population in an urban Chinese setting. We estimated that annually $1.24 \%$ of Hong Kong residents sustained pet-related household injury, which is similar to those reported by other developed countries. ${ }^{717}$ However, the projected size of people injured by pets (86 334) is much higher than the estimate from a previous study in Hong Kong on all causes of unintentional injuries $(n=5400) .{ }^{10}$ Such differences may be mainly due to the different scopes of an 'injury', as defined between the two studies: we investigated all pet-related injuries while the previous study only focused on injuries serious enough to limit the normal activities of a person. Most of the cases in our study did not seek any medical attention or did not take sick leave, reflecting that most pet-related injuries in Hong Kong are minor, therefore, were not captured by the previous study. One limitation of the study is over-representation of residents with higher education levels and doing white-collar jobs. One plausible explanation is due to the ability to make a connection during the times called. In Hong Kong, less educated people or those doing blue-collar jobs may work longer time or in the evening, which may have reduced their chances to be reached in this study. As education and occupation were not significantly related to pet-induced injury (table 4), the over-representation may not have much influence on the projected size of injured residents.

Consistent with many previous studies, we found pet ownership to be a strong risk factor for pet-related injuries. ${ }^{347918}$ However, the risk estimation of pet ownership in this study (adjusted OR=52.0) is much higher than the ones reported by these previous studies, which may be attributable to the discrepancies between studies, such as place of the injuries (the household setting in this study vs all settings in other studies), severity of a pet-related injury interested (eg, injuries received medical care in most previous studies), types of pets interested (eg, dogs only in most previous studies) and so on. Nevertheless, the increased number of pet owners, along with the fast-paced economic development in China, could result in increase of pet-related injuries. ${ }^{5}{ }^{6}$ Further studies should be conducted to confirm our findings and develop effective interventions to protect people from pet-related injuries.

In this study, females were more likely to be injured by a pet, which was consistent with the finding from the previous Hong Kong study, ${ }^{10}$ but contradictory with the results from studies in other countries. ${ }^{3} 718{ }^{19}$ It is not clear about the cause of the gender difference among Hong Kong residents and other populations. One possibility is that the two studies in Hong Kong reported on any pet-related injuries while the other studies focused only on dog-induced injuries. Further analysis in this study indicated that males were slightly more likely to have dog-induced injuries $(51.9 \%$ vs $48.1 \%)$, which may at least partly explain the difference. In contrast to the results from other studies, which showed that children 
Table 3 Further information of the participants with pet-related injury as the latest injury $(\mathrm{N}=64)$

\begin{tabular}{|c|c|c|}
\hline & $\mathbf{N}$ & Per cent \\
\hline \multicolumn{3}{|l|}{ Occurrence place of the injury } \\
\hline Living room & 47 & 73.4 \\
\hline Bedroom & 7 & 10.8 \\
\hline Bathroom & 5 & 7.8 \\
\hline Others & 5 & 7.8 \\
\hline \multicolumn{3}{|l|}{ Occurrence day of the injury } \\
\hline Weekday & 30 & 46.9 \\
\hline Weekend and holiday & 23 & 35.9 \\
\hline Don't know & 11 & 17.2 \\
\hline \multicolumn{3}{|l|}{ Body part injured $\ddagger$} \\
\hline Hands & 51 & 79.7 \\
\hline Legs & 10 & 15.6 \\
\hline Arms & 3 & 4.7 \\
\hline Head & 2 & 3.1 \\
\hline Body & 1 & 1.6 \\
\hline \multicolumn{3}{|l|}{ The pet involved } \\
\hline Cat & 33 & 51.6 \\
\hline Dog & 27 & 42.2 \\
\hline Otherst & 4 & 6.2 \\
\hline \multicolumn{3}{|l|}{ The pet ever received any vaccination } \\
\hline No & 11 & 17.2 \\
\hline Yes & 45 & 70.3 \\
\hline Don’t know & 8 & 12.5 \\
\hline \multicolumn{3}{|l|}{ Owner of the pet related } \\
\hline Yes & 59 & 92.2 \\
\hline No & 5 & 7.8 \\
\hline \multicolumn{3}{|l|}{ Interaction before attack } \\
\hline Playing with the pet & 38 & 59.4 \\
\hline Cleaning the pet & 6 & 9.4 \\
\hline Training the pet & 5 & 7.8 \\
\hline Others & 15 & 23.4 \\
\hline \multicolumn{3}{|l|}{ Ever attacked by the same pet before } \\
\hline Yes & 29 & 45.3 \\
\hline No & 35 & 54.7 \\
\hline \multicolumn{3}{|l|}{ Treatment of the injury } \\
\hline None & 15 & 23.4 \\
\hline Self-treatment & 40 & 62.5 \\
\hline $\begin{array}{l}\text { Others (including medical care and } \\
\text { treated by other persons) }\end{array}$ & 9 & 14.1 \\
\hline \multicolumn{3}{|c|}{ Absence from work or school caused by the injury } \\
\hline No & 13 & 20.3 \\
\hline Yes & 51 & 79.7 \\
\hline$<1$ day & 48 & 94.1 \\
\hline$\geq 1$ day & 3 & 5.9 \\
\hline \multicolumn{3}{|l|}{ Recovery time of the injury (days) } \\
\hline$<3$ & 45 & 70.3 \\
\hline $3-7$ & 13 & 20.3 \\
\hline$>7$ & 6 & 9.4 \\
\hline
\end{tabular}

$\ddagger$ As there were three injuries in which two body parts of the injured participants were injured, the sum of " $n$ " is 67 , not 64 . However, the denominator is still the number of injured persons $(\mathrm{N}=64)$, so the sum of "\%" is more than $100 \%$.

tOthers included rabbits, birds, guinea pigs, hamsters and so forth.

(especially those aged 5-9 years) were the most vulnerable cohort to sustain a pet-related injury, ${ }^{3} 7101819$ we found that young adults (aged 15-24 years) were at the highest risk among all the age cohorts. These differences could be explained by different data sources used across the studies. The results from the other studies were based on data collected in clinics and emergency departments. Adults are less likely than children to seek medical care in clinical settings after being injured by pets, especially when the injuries are minor, which might have resulted in an underestimation of petrelated injuries among adults in those studies (due to selection bias). However, data in our study were collected from a representative sample of the general population, which may have avoided such selection bias, therefore, reflects the real situation of pet-related injuries more accurately.

We found that higher monthly household income, greater housing living space and larger living area per capita (lower living density) were risk factors for petrelated injuries, while those having blue-collar jobs were less likely to be injured. These associations suggest affluence as a risk factor, which is consistent with other studies. ${ }^{7}$ When controlling for each other, the associations of occupation status and housing size with an injury were no longer significant, while monthly household income and living density remained significant and were positively related with the injuries. This may suggest that income and living density may be better indicators of affluence in urban Asian settings. In addition, we also found that unmarried participants were twice as likely to sustain a pet-related injury compared to married participants and the relationship did not change much after controlling for other factors. The reason is unknown as no previous study reported significant relationship between marital status and pet-related injuries. The most common reason for pet ownership is to get a companion to alleviate loneliness. ${ }^{5}$ One possible explanation is that unmarried participants may have more flexibility and willingness to raise a pet or playing with other people's pets, which may lead them to be at higher risk. However, our data failed to support this hypothesis as we neither observed significant relationship between marital status and pet ownership (pet ownership rates among married and unmarried participants were $12.9 \%$ and $13.1 \%$ respectively, $\mathrm{p}=0.795$ ), nor collected participants' behaviours with pets. Further studies are therefore warranted.

Given pet ownership is a strong risk factor in this study, its effect may not be fully controlled for in the multivariate analyses, we further estimated the risks of sociodemographic characteristics after stratification by pet ownership. The results revealed that only unmarried pet owners were at higher risk for pet-related injuries after adjustment for other factors, suggesting that unmarried pet owners should be put as the top priority when developing protective countermeasures in future, though the underpinning mechanism is still unclear. Given the statistical power to test significance reduced after the stratification, the relationship between pet-related injuries and other risk factors among pet owners need to be confirmed with a larger sample size in future. 
Table 4 Incidence rates of and risk estimations for pet-related injury in the past year $(\mathrm{N}=84$, with $\mathrm{p}<0.10$ in univariate analysis)

\begin{tabular}{|c|c|c|c|c|c|c|c|}
\hline & \multirow[b]{2}{*}{ Incidence rate (\%) } & \multicolumn{2}{|c|}{ Univariate analysis } & \multicolumn{2}{|c|}{ Multivariate Model 1} & \multicolumn{2}{|c|}{ Multivariate Model 2} \\
\hline & & $\overline{O R}_{\text {unadj }}$ & $(95 \% \mathrm{Cl}) \mathrm{OR}_{\mathrm{adj}}$ & $\overline{\mathbf{O R}}_{\text {unadj }}$ & $(95 \% \mathrm{Cl}) \mathrm{OR}_{\mathrm{adj}}$ & $\overline{\mathbf{O R}}_{\text {unadj }}$ & $(95 \% \mathrm{Cl}) \mathrm{OR}_{\mathrm{ad}}$ \\
\hline \multicolumn{8}{|l|}{ Gender } \\
\hline Male (ref.) & 1.04 & 1.00 & & 1.00 & & 1.00 & \\
\hline Female & 1.51 & 1.45 & (0.94 to 2.26$)$ & $1.73^{*}$ & (1.02 to 2.95$)$ & 1.54 & (0.89 to 2.67$)$ \\
\hline \multicolumn{8}{|l|}{ Age (years) } \\
\hline $0-4$ & 1.98 & 2.79 & (0.94 to8.27) & NA & & NA & \\
\hline $5-14$ & 1.31 & 1.84 & (0.83 to 4.08$)$ & NA & & NA & \\
\hline $15-24$ & 2.43 & $3.43^{*}$ & (1.85 to 6.37$)$ & NA & & NA & \\
\hline $25-44$ & 1.35 & 1.89 & (1.05 to 3.40$)$ & NA & & NA & \\
\hline$\geq 45$ (ref.) & 0.72 & 1.00 & & NA & & NA & \\
\hline \multicolumn{8}{|l|}{ Marital status } \\
\hline Married/cohabiting (ref.) & 0.85 & 1.00 & & 1.00 & & 1.00 & \\
\hline Single/divorced/widowed & 1.74 & $2.06^{*}$ & (1.31 to 3.24$)$ & $1.86^{*}$ & (1.10 to 3.14$)$ & $1.80^{*}$ & (1.04 to 3.10$)$ \\
\hline \multicolumn{8}{|c|}{ Education } \\
\hline Primary or below (ref.) & 0.62 & 1.00 & & NA & & NA & \\
\hline Secondary & 1.41 & 2.31 & (1.13 to 4.73 ) & NA & & NA & \\
\hline Postsecondary $†$ & 1.63 & 2.67 & (1.25 to 5.69$)$ & NA & & NA & \\
\hline \multicolumn{8}{|l|}{ Occupational status } \\
\hline White-collar job $\ddagger$ (ref.) & 1.70 & 1.00 & & NA & & NA & \\
\hline Blue-collar job§ & 0.42 & 0.25 & (0.06 to 1.02$)$ & NA & & NA & \\
\hline Housewives & 0.94 & 0.55 & (0.26 to 1.17$)$ & NA & & NA & \\
\hline Retired & 0.32 & $0.19^{\star}$ & (0.06 to 0.61$)$ & NA & & NA & \\
\hline Students & 1.70 & 1.00 & (0.61 to 1.65$)$ & NA & & NA & \\
\hline Others & 1.25 & 0.73 & (0.26 to 2.06$)$ & NA & & NA & \\
\hline \multicolumn{8}{|c|}{ Monthly household income (HK\$q) } \\
\hline$<10000$ (ref.) & 0.32 & 1.00 & & 1.00 & & 1.00 & \\
\hline $10000-19999$ & 1.32 & 4.20 & (1.24 to 14.2$)$ & $10.9^{*}$ & $(1.44$ to 83.0$)$ & $6.85^{\star \star}$ & (0.89 to 52.7 ) \\
\hline $20000-29999$ & 1.15 & 3.64 & (1.02 to 12.9$)$ & $9.21^{*}$ & (1.17 to 72.4$)$ & $6.08^{\star *}$ & (0.76 to 48.7$)$ \\
\hline$\geq 30000$ & 1.93 & $6.18^{*}$ & (1.89 to 20.2$)$ & $14.7^{\star \star}$ & (2.00 to 108.3 ) & $7.60^{*}$ & (1.01 to 57.1$)$ \\
\hline \multicolumn{8}{|l|}{ Size of living area $\left(\mathrm{ft}^{2} \neq \ddagger\right)$} \\
\hline$\leq 400$ (ref.) & 0.78 & 1.00 & & NA & & NA & \\
\hline $401-600$ & 0.72 & 0.92 & (0.43 to 1.96$)$ & NA & & NA & \\
\hline $601-700$ & 1.74 & 2.25 & (1.08 to 4.69$)$ & NA & & NA & \\
\hline$>700$ & 1.88 & $2.42^{*}$ & (1.25 to 4.69$)$ & NA & & NA & \\
\hline \multicolumn{8}{|c|}{ Living density ( $\mathrm{ft}^{2} /$ person $\left.\ddagger\right)$ ) } \\
\hline$<120$ (ref.) & 0.59 & 1.00 & & 1.00 & & 1.00 & \\
\hline $120-159$ & 1.00 & 1.70 & (0.72 to 3.98$)$ & 1.31 & (0.51 to 3.37$)$ & 1.05 & (0.39 to 2.77 ) \\
\hline $160-249$ & 1.44 & 2.45 & (1.16 to 5.20$)$ & 1.89 & (0.82 to 4.34$)$ & 1.19 & (0.50 to 2.86$)$ \\
\hline$\geq 250$ & 1.65 & 2.81 & (1.27 to 6.23$)$ & $2.87^{\star}$ & (1.21 to 6.82$)$ & 1.45 & (0.58 to 3.61$)$ \\
\hline \multicolumn{8}{|l|}{ Pet ownership } \\
\hline No (ref.) & 0.19 & 1.00 & & - & & 1.00 & \\
\hline Yes & 8.56 & $48.3^{*}$ & (25.5 to 91.4 ) & - & & $52.0^{* \star *}$ & (22.1 to 122.4 ) \\
\hline
\end{tabular}

*Significant difference level at $p=0.05$ reached in the univariate analysis. ${ }^{* *}$ Significant difference level at $p=0.01$. ${ }^{* *}$ Significant difference level at $\mathrm{p}=0.001$. Bonferroni correction was applied to correct multiple testing. A significance level of $a=0.00417(0.05 / 12)$ was therefore adopted. †Post-secondary education included non-degree and degree courses.

†White-collar job: including manager and administrators, professionals, associate professionals, clerical support workers and service and sales workers.

§Blue-collar job: including craft and related workers, plant and machine operators, elementary occupations and skilled agricultural and fishery workers.

ףAnnual exchange rate in 2009: HK\$1=US\$0.129 (US $\$ 1=\mathrm{HK} \$ 7.75$ ); HK\$10 000=US\$1290; HK\$20 000=US\$2580; HK\$30 000=US\$3870. $\neq \ddagger 1 \mathrm{ft}^{2}=0.093 \mathrm{~m}^{2}\left(1 \mathrm{~m}^{2}=10.76 \mathrm{ft}^{2}\right)$.

$\mathrm{NA}$, the variables were selected but excluded from the Model 1 according to the variable selection method with $p<0.10$ as the entry and removal criteria; ref., reference group; -, pet ownership was not put in the Model 1.

Most pet-related injuries in our study involved a person's hands, which is consistent with the results from previous studies. ${ }^{3} 71819$ Although injuries examined in this study were not severe, it should be noted that animals, regardless of the types involved, may carry many diseases that are readily transmissible to human beings, and many of those diseases can be vaccinated against. One such disease is rabies, especially from dog 
bites. Rabies is nearly always fatal, and there is no specific treatment. ${ }^{8}$ The microorganism most commonly isolated from wounds by cat bites is Pasteurella multocida. Injuries caused by cat bites and scratches may result in cat-scratch disease, which is caused by the bacterium Bartonella henselae. ${ }^{2}{ }^{20}$ Another cat-associated infection is toxoplasmosis, which is caused by the parasite Toxoplasma gondii and manifested as a congenital infection. ${ }^{20}$ It should be noted that Toxoplasma infection rates in cat bites have been reported to be between $30-50 \%$, which is much higher than the rate of infection for $\operatorname{dog}$ bites $(4 \%){ }^{21}$ Unfortunately, only $70.3 \%$ of the pets involved in this study had received vaccinations before, with an even lower vaccination rate of $63.6 \%$ being found for cats. As cats are one of the most popular types of pets kept in urban households, cat owners need to be educated about the risks of injuries caused by cats and empowered by effective means to protect themselves from such injuries.

\section{Limitations}

The results of this study are subject to several limitations. This is a cross-sectional study, thus, it cannot draw a conclusion on the cause-effect relationship. The data on pet-related injuries are self-reported and therefore subject to potential recall bias. This study focuses on petrelated injuries that occurred in a household setting and does not include pet-related injuries that occurred beyond this setting (eg, roads, parks). As the number of participants reporting pet-related injuries was relatively small in this study $(n=84)$, the estimations of the risk factors are inconclusive. It is possible that the associations observed in this study may be just a random phenomenon. Owing to the time constraint, the detailed injury information was collected only from those petrelated injuries which were reported as the most recent injury by the participants. Thus, the results (table 3) may not reflect the real situation of all pet-related injuries in this study. However, as there was no significant difference between the two groups (all petrelated injuries and those as the most recent injury) as shown in table 2, the results may not be biased much from those of all the injuries. Further studies with a prospective longitudinal design are needed to capture all pet-related injuries and confirm the associations observed in this study. Moreover, we did not collect detailed information of pet ownership, for example, $\operatorname{dog} /$ cat breeds, history of raising pets, numbers of concurrent pets, the time length of having pets, knowledge and practice on raising pets, all of which are needed to develop effective protection measures and therefore should be addressed in future studies. Finally, some households in this study might keep pets under unlawful circumstances, and therefore participants might be less likely to report owning pets. Thus, the number of pet owners might be under-reported.

\section{CONCLUSIONS}

We estimate that more than 86000 residents in Hong Kong sustained a non-fatal pet-related injury in the household setting in the past 12 months, with a personbased incidence rate of $1.24 \%$. Most of the injuries reported are minor, induced by cats or dogs, with the wounds sustained affecting a person's hands and dealt with by the victims. Pet ownership is a strong risk factor for such an injury. Unmarried and affluent people are also at higher risk, especially unmarried pet owners. Given the increasing trend in pet ownership, it is necessary to take effective measures to protect people from pet-related injuries, especially the unmarried pet owners. Further studies with a prospective longitudinal design should include pet-related injuries that happen outside a household setting.

\section{Author affiliations}

${ }^{1} \mathrm{JC}$ School of Public Health and Primary Care, The Chinese University of Hong Kong, Hong Kong SAR, China

${ }^{2}$ Department of Physical Education, Hong Kong Baptist University, Hong Kong SAR, China

${ }^{3}$ Injury Prevention Research Center, Medical College of Shantou University, Shantou, China

Acknowledgements The authors would like to thank Mr Zhe Huang for the research support during the project, Dr Chunlan Guo and Dr Susan Wang for the editing and administrative supports.

Contributors EYYC and YG participated in planning the study, data collection, interpreting the results and final paper writing. $L L$ and PYL participated in data collection, interpreting the results and final paper writing. EYYC obtained research funding. YG wrote the first draft of the article. All authors were involved in planning the article, critical review and editing of the first draft and subsequent revisions to the paper. All authors read and approved the final manuscript.

Funding This project is funded by Health and Health Services Research Fund, Food and Health Bureau, Government of the Hong Kong SAR (grant no. 06070491). The content is solely the responsibility of the authors and does not necessarily represent the official views of the Department of Health, HKSAR.

Competing interests None declared.

Ethics approval Survey and Behavioural Research Ethics Committee at the Chinese University of Hong Kong.

Provenance and peer review Not commissioned; internally peer reviewed.

Data sharing statement No additional data are available.

Open Access This is an Open Access article distributed in accordance with the Creative Commons Attribution Non Commercial (CC BY-NC 4.0) license, which permits others to distribute, remix, adapt, build upon this work noncommercially, and license their derivative works on different terms, provided the original work is properly cited and the use is non-commercial. See: http:// creativecommons.org/licenses/by-nc/4.0/

\section{REFERENCES}

1. Lessenger JE. Agricultural Medicine: a practical guide. New York USA: Springer, 2006.

2. Palacio J, León-Artozqui M, Pastor-Villalba E, et al. Incidence of and risk factors for cat bites: a first step in prevention and treatment of feline aggression. J Feline Med Surg 2007;9:188-95.

3. Centers for Disease Control and Prevention. Nonfatal dog biterelated injuries treated in hospital emergency departments-United States, 2001. Morb Mortal Wkly Rep 2003;52:605-10. 
4. Stevens JA, Haileyesus T, Centers for Disease Control and Prevention. Nonfatal fall-related injuries associated with dogs and cats--United States, 2001-2006. Morb Mortal Wkly Rep 2009;58:277-81.

5. Batson A. Global companion animal ownership and trade: project summary, June 2008. 2008. https://www.zotero.org/groups/ chagasepid8515/items/PHEQZ2HV (accessed $20 \mathrm{Jul} 2015$ ).

6. Zhuang J. China: changing attitudes to pet ownership drive pet food sales. 2005. http://blog.euromonitor.com/2005/03/china-changingattitudes-to-pet-ownership-drive-pet-food-sales.html (accessed 20 Jul 2015).

7. Ozanne-Smith J, Ashby K, Stathakis VZ. Dog bite and injury prevention--analysis, critical review, and research agenda. Inj Prev 2001;7:321-6.

8. Fèvre EM, Kaboyo RW, Persson V, et al. The epidemiology of animal bite injuries in Uganda and projections of the burden of rabies. Trop Med Int Health 2005;10:790-8.

9. Georges K, Adesiyun A. An investigation into the prevalence of dog bites to primary school children in Trinidad. BMC Public Health 2008;8:85.

10. Centre for Health Protection, HKSAR. Injury Survey 2008. http:// www.chp.gov.hk/files/pdf/injury_survey_eng.pdf (accessed 20 Jul 2015).

11. Census and Statistics Department. Hong Kong Annual Digest of Statistics: 2012 Edition. 2012. http://www.censtatd.gov.hk/ (accessed 13 Mar 2013)
12. Chan EYY, Kim JH, $\mathrm{Ng} \mathrm{Q}$, et al. A descriptive study of nonfatal, unintentional home-based injury in urban settings: evidence from Hong Kong. Asia Pacific J Public Health 2008;20(Suppl):39-48.

13. Lau JTF, Yeung NCY, Choi KC, et al. Acceptability of $\mathrm{A} / \mathrm{H} 1 \mathrm{~N} 1$ vaccination during pandemic phase of influenza $A / H 1 N 1$ in Hong Kong: population based cross sectional survey. BMJ 2009;339 (oct27 1):b4164.

14. McGee K, Sethi D, Peden M, et al. Guidelines for conducting community surveys on injuries and violence. Int $\mathrm{J}$ Inj Contr Saf Promot 2004;11:303-6.

15. Chan EYY, Kim JH, Griffiths SM, et al. Does living density matter for nonfatal unintentional home injury in Asian urban settings? Evidence from Hong Kong. J Urban Health 2009;86:872-86.

16. Woodward M. Epidemiology: study design and data analysis. 2nd edn. Boca Raton: Chapman \& Hall/CRC, 2005.

17. Thomas N, Brook I. Animal bite-associated infections: microbiology and treatment. Expert Rev Anti-infe 2011;9:215-26.

18. Vargo D, DePasquale JM, Vargo AM. Incidence of dog bite injuries in American Samoa and their impact on society. Hawaii $J$ Med Public Health 2012;71:6-12.

19. Quirk JT. Non-fatal dog bite injuries in the U.S.A., 2005-2009. Public Health 2012;126:300-2.

20. Sandora TJ, Bernstein HH. Neonatal jaundice, animal-induced injuries, and immunizations. Curr Opin Pediatr 2001;13:377-85.

21. Smith PF, Meadowcroft AM, May DB. Treating mammalian bite wounds. J Clin Pharm Ther 2000;25:85-99. 